\title{
Attitudes and Usage of Face Masks During the COVID-19 Pandemic Among Occupational Therapy Professionals in Texas
}

\section{Stephen A. Cage}

The University of Texas at Tyler, sacage@uncg.edu

Diane P. Brown

The University of Texas at Tyler, dbrown@uttyler.edu

Brandon J. Warner

Grand Canyon University, brandon.warner@gcu.edu

Diana M. Gallegos

University of Texas at Tyler, dgallegos@uttyler.edu

Heidi M. Cage

Encompass Health, heidi.heuer@gmail.com

Follow this and additional works at: https://nsuworks.nova.edu/ijahsp

Part of the Occupational Therapy Commons

\section{Recommended Citation}

Cage SA, Brown DP, Warner BJ, Gallegos DM, Cage HM. Attitudes and Usage of Face Masks During the COVID-19 Pandemic Among Occupational Therapy Professionals in Texas. The Internet Journal of Allied Health Sciences and Practice. 2022 Jan 03;20(1), Article 5.

This Manuscript is brought to you for free and open access by the College of Health Care Sciences at NSUWorks. It has been accepted for inclusion in Internet Journal of Allied Health Sciences and Practice by an authorized editor of NSUWorks. For more information, please contact nsuworks@nova.edu. 


\title{
Attitudes and Usage of Face Masks During the COVID-19 Pandemic Among Occupational Therapy Professionals in Texas
}

\begin{abstract}
Purpose: Following the widespread transmission of severe acute respiratory syndrome coronavirus 2 (SARS-CoV-2), multiple business and schools drastically reduced face-to-face services. Additionally, many state and local governments enacted face mask mandates and other legislations aimed at decreasing the spread of the virus. Current research is being conducted to evaluate the epidemiology, recognition, treatment, and prevention of coronavirus disease 2019 (COVID-19), the disease associated with SARSCoV-2. At the time of this study, there is no published research on the attitudes and usage of face masks or face coverings among certified occupational therapy professionals during the COVID-19 Pandemic. The purpose of this study is to describe the attitudes and usage of face masks or face coverings among occupational therapy professionals in the state of Texas during the COVID-19 pandemic. Methods: A total of 107 occupational therapy professionals (age $=42 \pm 12$, years of certified experience $=18 \pm 11$ ) opened the survey link and completed the instrument. Participants were sent an electronic survey via email that collected demographic information and assessed attitudes and usage of face masks or face coverings. Data was downloaded and analyzed using a commercially available statistics package. Results: The overwhelming majority of occupational therapy professionals in this study agreed on some level that the use of face masks to mitigate the transmission of SARS-CoV2 was strongly supported by the available evidence (Strongly Agree $=65.4 \%$, Agree $=19.6 \%$, Somewhat Agree $=5.6 \%$ ). Most occupational therapy professionals also reported that their institutions currently had a mandate in place requiring face masks during patient encounters and coworker interactions (Patient Encounters $=94.4 \%$, Coworker Interactions $=86.9 \%$ ). Most occupational therapy professionals reported wearing face masks the majority of the time when entering public spaces. Occupational therapy professionals cited the influence of their personal use of face masks was for personal health, health of those in their household, and the health of their patients. Conclusions: The findings of this study suggest a majority of occupational therapy professionals in Texas are wearing face masks or face coverings, even when not actively involved in patient care or other aspects of their jobs. Future research should be conducted to assess the use of face masks among other allied health care professions
\end{abstract}

\section{Author Bio(s)}

S. Andrew Cage, M.Ed., LAT, ATC, is the Head Athletic Trainer and an Instructor of Health \& Kinesiology at the University of Texas at Tyler in Tyler, TX. He is also a licensed and certified athletic trainer.

Diane Brown, PhD, OTR, is the MOT Program Director and a Clinical Associate Professor or Health \& Kinesiology at the University of Texas at Tyler in Tyler, TX. She is also a fully credentialed occupational therapist.

Brandon Warner, M.Ed., LAT, ATC, is the Athletic Training Program Director and an Associate Professor at Grand Canyon University in Phoenix, AZ. Brandon is also a licensed and certified athletic trainer.

Diana M. Gallegos, MS, LAT, ATC, is the Assistant Athletic Trainer and an Adjunct Instructor in Health \& Kinesiology at the University of Texas at Tyler in Tyler, TX. Diana is also a licensed and certified athletic trainer.

Heidi M. Cage, OTR, is an occupational therapist for Encompass Health in Tyler, TX. Heidi is also a fully credentialed occupational therapist. 


\title{
1IVAHSP \\ The Internet Journal of Allied Health Sciences and Practice \\ Dedicated to allied health professional practice and education \\ Vol. 20 No. 1 ISSN 1540-580X
}

\section{Attitudes and Usage of Face Masks During the COVID-19 Pandemic Among Occupational Therapy Professionals in Texas}

\author{
Stephen A. Cage ${ }^{1}$ \\ Diane P. Brown ${ }^{1}$ \\ Brandon J. Warner ${ }^{2}$ \\ Diana M. Gallegos ${ }^{1}$ \\ Heidi M. Cage ${ }^{3}$ \\ 1. University of Texas at Tyler \\ 2. Grand Canyon University \\ 3. Encompass Health
}

United States

\begin{abstract}
Purpose: Following the widespread transmission of severe acute respiratory syndrome coronavirus 2 (SARS-CoV-2), multiple business and schools drastically reduced face-to-face services. Additionally, many state and local governments enacted face mask mandates and other legislations aimed at decreasing the spread of the virus. Current research is being conducted to evaluate the epidemiology, recognition, treatment, and prevention of coronavirus disease 2019 (COVID-19), the disease associated with SARSCoV-2. At the time of this study, there is no published research on the attitudes and usage of face masks or face coverings among certified occupational therapy professionals during the COVID-19 Pandemic. The purpose of this study is to describe the attitudes and usage of face masks or face coverings among occupational therapy professionals in the state of Texas during the COVID-19 pandemic. Methods: A total of 107 occupational therapy professionals (age $=42 \pm 12$, years of certified experience $=18 \pm 11$ ) opened the survey link and completed the instrument. Participants were sent an electronic survey via email that collected demographic information and assessed attitudes and usage of face masks or face coverings. Data was downloaded and analyzed using a commercially available statistics package. Results: The overwhelming majority of occupational therapy professionals in this study agreed on some level that the use of face masks to mitigate the transmission of SARS-CoV2 was strongly supported by the available evidence (Strongly Agree $=65.4 \%$, Agree $=19.6 \%$, Somewhat Agree $=5.6 \%$ ). Most occupational therapy professionals also reported that their institutions currently had a mandate in place requiring face masks during patient encounters and coworker interactions (Patient Encounters $=94.4 \%$, Coworker Interactions $=86.9 \%$ ). Most occupational therapy professionals reported wearing face masks the majority of the time when entering public spaces. Occupational therapy professionals cited the influence of their personal use of face masks was for personal health, health of those in their household, and the health of their patients. Conclusions: The findings of this study suggest a majority of occupational therapy professionals in Texas are wearing face masks or face coverings, even when not actively involved in patient care or other aspects of their jobs. Future research should be conducted to assess the use of face masks among other allied health care professions.
\end{abstract}

Keywords: occupational therapy, COVID-19, face masks 


\section{INTRODUCTION}

Coronavirus disease 19 (COVID-19) is a respiratory disease caused by the virus severe acute respiratory syndrome coronavirus 2 (SARS-CoV-2). ${ }^{1}$ COVID-19 was initially described in late 2019 in Wuhan, China. ${ }^{1}$ The disease has been shown to be highly infectious and features symptoms including fever, dry cough, sore throat, fatigue, loss of smell, loss of taste, muscle and joint pain, shortness of breath, nausea, vomiting, and diarrhea. ${ }^{1}$ In severe cases of COVID-19, patients have developed potentially fatal pneumonia, septic shock, metabolic acidosis, and coagulation dysfunction. ${ }^{2}$ Presently, there is no proven treatment or vaccine. Thus, the primary recommendations to mitigate the spread of COVID-19 have been social distancing, recognition through testing, contact tracing, enhanced hygiene precautions, and face coverings. ${ }^{3-6}$

As the COVID-19 pandemic progressed, governments and organizations began passing legislation and rulings in an attempt to slow the transmission of COVID-19. The National Collegiate Athletic Association (NCAA) chose to cancel all remaining spring and winter championships. ${ }^{7}$ Additionally, most higher education institutions canceled the remainder of their athletics seasons. ${ }^{8}$ Secondary schools also suspended athletic activities for the remainder of the 2020 spring semester. ${ }^{9}$ Not only were athletic activities canceled, the majority of higher education institutions and secondary schools in the United States canceled face-to-face instruction. ${ }^{10,11}$ As institutions and communities began to reopen following closures, many areas enacted rules requiring the use of face masks or face coverings. ${ }^{12-15}$ However, some communities have chosen to leave the use of face masks up to individual responsibility. 5,6

Research is being conducted to evaluate the epidemiology, recognition, treatment, and prevention of COVID-19.1-4 To the authors' knowledge, there is no published research on the attitudes and usage of face masks among occupational therapy professionals in the state of Texas during the COVID-19 pandemic. Thus, the purpose of this study was to describe the attitudes and usage of face masks among credentialed occupational therapy professionals in the state of Texas.

\section{METHODS \\ Design}

This study was conducted using a cross-sectional design utilizing an internet-based survey for data collection.

\section{Respondents}

Respondents were recruited for this study by emailing the attendees of the 2020 Texas Occupational Therapy Association Annual Symposium. In total, 782 emails were sent to potential participants. A total of 107 occupational therapy professionals (age $=42 \pm$ 12 , years of certified experience $=18 \pm 11$ ) opened the survey link and completed the instrument. This represented a $13.7 \%$ response rate. Demographic information for participants is presented in Table 1. All participants were informed of the survey's purpose and informed consent was obtained.

Table 1. Totals and percentages for participant demographic information.

\begin{tabular}{|l|l|l|}
\hline Demographic Factor & Criteria & Responses \\
\hline Sex & Female & $90,84.1 \%$ \\
& Male & $17,15.9 \%$ \\
\hline Clinical Practice Setting & Outpatient & $32,29.9 \%$ \\
& Inpatient & $39,36.4 \%$ \\
& Pediatrics & $29,27.1 \%$ \\
& Skilled Nursing & $21,19.6 \%$ \\
& Adult & $25,23.4 \%$ \\
& School District & $12,11.2 \%$ \\
\hline Highest Degree Earned & Professional Associate's & $12,11.2 \%$ \\
& Professional Bachelor's & $29,27.1 \%$ \\
& Professional Master's & $45,42.1 \%$ \\
& Post-Professional Clinical Doctorate & $9,8.4 \%$ \\
& Academic Doctorate & $12,11.2 \%$ \\
\hline
\end{tabular}

\section{Instrumentation}

Following the informed consent, internal review board approval, and demographics section, the survey included questions about practice setting and whether the participant had been allowed to continue working or return to work during the COVID-19 pandemic. The participants were also asked whether or not they were subject to any organizational or government mandates to wear face 
masks at work or in public. Other questions gathered information on the attitudes of participants toward wearing face masks, how often they wore face masks outside of work while in public, and what their primary considerations were when deciding whether or not to wear face masks.

The survey consisted of 18 total questions. These questions included: one question regarding consent to participate in the study, two fill in the blank and three multiple choice questions regarding demographic information, 10 multiple choice questions regarding attitudes and usage of face masks at work and in public, and two ranking questions regarding considerations for whether or not to wear a face mask.

\section{Procedures}

An email was sent to occupational therapists and occupational therapy assistants who had attended the 2020 Texas Occupational Therapists' Association Annual Symposium. These individuals were asked to complete the survey as truthfully as possible. The email included an invitation to participate in an electronic survey via a link from a web-based survey company (Qualtrics Inc., Provo, UT) in July 2020. A follow up email was sent the week after the initial invitation, and the survey was closed a week later. The initial message included information about the investigators, the purpose of the study, the purpose of the survey, and also informed the participants that they could opt out of the survey at any time.

\section{Data Analysis}

Information from participant responses was downloaded and analyzed using a commercially available statistics package (SPSS Version 26, IBM, Armonk, NY). A total of 107 occupational therapy professionals responded, consented and completed the study. All 107 responses were included in the data analysis. Measures of central tendency (percentages, frequencies) were calculated where appropriate.

\section{RESULTS}

\section{Attitudes Toward the Use of Face masks or Face Coverings}

The majority of responding occupational therapy reporter agreed on some level that the use of face masks or face coverings to mitigate the spread of COVID-19 was strongly supported by the available evidence. More respondents reported considering personal and community safety rather than concerns about the perceptions of others or having their liberties infringed upon when deciding whether or not to wear a mask in public. Table 2 provides a breakdown of the questions that gathered information on respondents' attitudes toward the use of face masks or face coverings in public.

Table 2. Responses for questions on the attitudes toward the use of face masks or face coverings in public.

\begin{tabular}{|l|l|}
\hline Statement & Most Common Responses (\%) \\
\hline $\begin{array}{l}\text { The current available evidence strongly supports the use of face masks or face } \\
\text { coverings when interacting with others to decrease the transmission of COVID- } \\
19 .\end{array}$ & $\begin{array}{l}\text { Strongly Agree, } 70(65.4 \%) \\
\text { Agree, 21 (19.6\%) } \\
\text { Somewhat Agree, } 6(5.6 \%)\end{array}$ \\
\hline $\begin{array}{l}\text { I feel safer/would feel safer if my institution required face masks or face } \\
\text { coverings at work. }\end{array}$ & $\begin{array}{l}\text { Strongly Agree, } 77(72 \%) \\
\text { Agree, 17 (15.9\%) } \\
\text { Neither Agree Nor Disagree, } 4(3.7 \%)\end{array}$ \\
\hline $\begin{array}{l}\text { I feel safer/would feel safer if my local or state government required face masks } \\
\text { or face coverings in public. }\end{array}$ & $\begin{array}{l}\text { Strongly Agree, } 75(70.1 \%) \\
\text { Agree, 17 (15.9\%) } \\
\text { Somewhat Agree, } 6(5.6 \%)\end{array}$ \\
\hline $\begin{array}{l}\text { I would prefer that wearing face masks or coverings be left to individual } \\
\text { responsibility rather than to a mandate from my institution. }\end{array}$ & $\begin{array}{l}\text { Strongly Disagree, } 52(48.6 \%) \\
\text { Disagree, 30 }(28 \%) \\
\text { Strongly Agree, } 10(9.3 \%)\end{array}$ \\
\hline $\begin{array}{l}\text { I would prefer that wearing face masks or coverings be left to individual } \\
\text { responsibility rather than to a mandate from my state or local government. }\end{array}$ & $\begin{array}{l}\text { Strongly Disagree, } 53(49.5 \%) \\
\text { Disagree, 25 (23.4\%) } \\
\text { Strongly Agree, } 10(9.3 \%)\end{array}$ \\
\hline $\begin{array}{l}\text { Please rank the following considerations when deciding whether or not to wear a } \\
\text { face mask or face covering outside of work. }\end{array}$ & $\begin{array}{l}\text { Personal Safety, } 68(63.6 \%) \\
\text { Community Safety, } 29(27.1 \%)\end{array}$ \\
& $\begin{array}{l}\text { Public Perception if I did not Wear a Face } \\
\text { Mask, 2 (1.9\%) }\end{array}$ \\
\hline
\end{tabular}


Please rank the following parties based off of how strongly you consider them when deciding whether or not to wear a face mask outside of work.
Yourself, $43(40.2 \%)$

Family Members in Your Household, 22

$(20.6 \%)$

Your Patients, $20(18.7 \%)$

\section{Face Mask Usage at Work and in Public}

Out of the responding occupational therapy professionals, $94.4 \%$ reported that their employer had allowed them to return to work $(n=101)$. The majority of participants reported being required to wear masks during patient interactions $(94.4 \%, n=101)$ and during coworker interactions $(86.9 \%, n=93)$. Table 3 describes how often occupational therapy professionals reported wearing masks in public spaces when not working.

Table 3. Frequency of face mask use in public when not at work among occupational therapy professionals.

\begin{tabular}{|c|c|}
\hline Frequency & Responses \\
\hline $100 \%$ of the time & $78,72.9 \%$ \\
\hline $75 \%$ of the time & $19,17.8 \%$ \\
\hline $50 \%$ of the time & $5,4.7 \%$ \\
\hline $25 \%$ of the time & $3,2.8 \%$ \\
\hline $0 \%$ of the time & $2,1.9 \%$ \\
\hline
\end{tabular}

\section{DISCUSSION}

The purpose of this study was to describe the attitudes of credentialled occupational therapy professionals toward the use of face masks or face coverings during the COVID-19 Pandemic. A secondary purpose to this study was to describe the usage of face masks among credentialled occupational therapy professionals outside of work.

Our findings suggest that the majority of respondents surveyed agreed on some level that current evidence strongly supports the use of face masks or face coverings to decrease the transmission of COVID-19 (Strongly Agree $=65.4 \%$, Agree $=19.6 \%$, Somewhat Agree $=5.6 \%$ ). Furthermore, occupational therapy professionals reported that most would feel safer if there were mandates from their employer or government officials requiring the use of face masks in public. This suggests that the majority of the athletic trainers surveyed feel that face masks are a useful tool for mitigating the spread of COVID-19.

Most occupational therapy professionals stated that their employer had required or allowed them to return to work. At the organizations where occupational therapy professionals had returned, the majority required the use of face masks during patient and coworker interactions. When not at work, most occupational therapy professionals reported wearing face masks in public spaces at least $75 \%$ of the time. Only $1.9 \%$ of surveyed occupational therapy professionals reported never wearing a face mask in public spaces. This suggests that occupational therapy professionals are wearing face masks in public even when not at work during the COVID-19 pandemic. The most important considerations for these behaviors appear to be personal safety, household safety, and the health of patients. This concern for patients could be attributed to the fact that many occupational therapy professionals work with patients that could be considered high risk for severe symptoms related to COVID-19.

\section{Limitations}

A possible limitation of this study was the relatively low number of responses. While the total number of responses is similar to other survey-based studies conducted on occupational therapy professionals, an exhaustive and definitive statement on the attitudes and usage of face masks among occupational therapy professionals would require a larger scale study. ${ }^{16,17}$ The completion of this study provides a framework for conducting a study that collects data from a larger number of respondents.

There is a need for additional research into the attitudes, moods, and behaviors of occupational therapy professionals and other allied healthcare professionals related to the COVID-19 Pandemic. A previous study investigated the moods of athletic trainers following the 2020 academic and athletic spring semester, and suggested athletic trainers were experiencing both anxiety and depression. ${ }^{18}$ Given allied healthcare professionals' role in providing day-to-day patient care, it is imperative to evaluate the stresses and obstacles they are encountering due to the COVID-19 Pandemic.

\section{CONCLUSION}

In conclusion, the majority of surveyed occupational therapy professionals believe the currently available evidence supports the use of face masks or face coverings to decrease the transmission of COVID-19. Occupational therapy professionals reported the 
majority of their employers required face masks during patient and coworker encounters, which appeared to make them feel safer in their workspace. The majority of occupational therapy professionals reported placing personal, patient, and community safety ahead of public perception and concerns over personal liberties being infringed upon when considering whether to wear a face mask in public. As occupational therapy professionals and other allied healthcare professionals move forward, it is important to consider the best implementation and enforcement of using personal protective equipment.

\section{REFERENCES}

1. Zhong BL, Luo W, Mei LH, Zhang QQ, Liu XG, Li WT, Li Y. Knowledge, attitudes, and practices toward COVID-19 among Chinese residents during the rapid rise period of the COVID-19 outbreak: A quick online cross-sectional survey. International Journal of Biological Sciences. 2020;16(10):1745-1752.

2. Chen N, Zhou M, Dong X, Qu J, Gong F, Han Y, et al. Epidemiological and clinical characteristics of 99 cases of 2019 novel coronavirus pneumonia in Wuhan, China: A descriptive study. Lancet. 2020;395:507-513.

3. Patel R, Babady E, Theel ES, Storch GA, Pinsky BA, George KS, Smith TC, Bertuzzi S. Report from the American Society for Microbiology COVID-19 International Summit, 23 March 2020: Value of diagnostic testing for SARS-CoV2/COVID-19. American Society for Microbiology. 2020;11(2).

4. Ebrahim SH, Memish ZA. COVID-19 - The role of mass gatherings. Travel Medicine and Infectious Disease. 2020.

5. Zhang R, Li Y, Zhang AL, Wang Y, Molina MJ. Identifying airborne transmission as the dominant route for the spread of COVID-19. Proceeds of the National Academy of Sciences. 2020.

6. Eikenberry SE, Mancuso M, Iboi E, Phan T, Eikenberry K, Kuang Y, Kostelich E, Gumel AB. To mask or not to mask: Modeling the potential for face mask use by the general public to curtail the COVID-19 pandemic. Infectious Disease Modeling. 2020;5:293-308.

7. ESPN. Coronavirus cancellations and reactions in sport. Retrieved from https://www.espn.com/espn/story/_/id/28871525/coronavirus-cancellations-reactions-sports. Published March 2020.

8. ESPN. SEC becomes latest conference to cancel sports for 2019-2020. Retrieved from https://www.espn.com/collegesports/storyl_lid/28917683/sec-becomes-latest-conference-cancel-sports-2019-20. Published March 2020.

9. The New York Times. High school sports pushed out of bounds by the pandemic. Retrieved from https://www.nytimes.com/2020/04/26/sports/coronavirus-high-school-sports.html. Published April 2020.

10. CNN. Universities begin considering the possibility of cancelling in person classes until 2021. Retrieved from https://www.cnn.com/2020/04/14/us/university-may-cancel-classes-fall-2021-trnd/index.html. Published April 2020.

11. The New York Times. As schools look for guidance, educators are left asking, 'What?'. Retrieved from https://www.nytimes.com/2020/03/18/us/politics/education-schools-coronavirus.html. Published March 2020.

12. California Department of Public Health. Guidance for the use of face coverings. Retrieved from https://www.cdph.ca.gov/Programs/CID/DCDC/ CDPH\%20Document\%20Library/COVID-19/Guidance-for-FaceCoverings_06-18-2020.pdf.

13. KKTV. New Mexico's governor requires everyone to wear a face mask in public. Retrieved from https://www.kktv.com/content/news/New-Mexicos-governor-requires-everyone-to-wear-face-masks-in-public570456461.html.

14. Winston Salem Journal. Face coverings now required in most campus spaces at UNCG. Retrieved from https://www.journalnow.com/news/local/face-coverings-now-required-in-most-campus-spaces-atuncg/article_000d043a-1767-58d6-a913-930842e2701d.html.

15. Texas Tribune. Texas' biggest public universities will require masks this fall. Enforcement will be a challenge. Retrieved from https://www.texastribune.org/2020/06/24/ut-tamu-texas-universities-face-masks/

16. Usher R, Sapleton T. Occupational therapy and decision-making capacity assessment: A survey of practice in Ireland. Australian Occupational Therapy Journal. 2020;67:110-120.

17. Stein Duker $\mathrm{LI}$, Sleight AG. Occupational therapy practice in oncology care: Results from a survey. Nursing \& Health Sciences. 2019;21:164-170. 